\title{
Corporate Community Engagement: Literature Search for Construct Validation. A Case of the Extractive Industry in Zimbabwe
}

\author{
Pumela Msweli, Tawaziwa Wushe, and Wedzerai C. Mandudzo
}

\begin{abstract}
This literature review examines evidence for corporate community engagement, it maps out its field as it currently stands, and identifies the gaps in what is currently known on corporate community engagement. It also assesses on the best way to engage communities in extraction of minerals by both extractive industries and research. The review was done in 2012. The study is organised around three research questions germane to corporate community engagement. The first question is: What are the factors that trigger conflict between corporates and local communities? The second question is: How do local communities define meaningful corporate engagement? The third question is shaped by evidence in literature which supports the notion that community engagement is a process of inclusive participation that supports mutual respect of values and actions for authentic partnership of people in the same geographic proximity. The question is: using the levels of participation how can the awaked social energies in communities be harnessed to develop corporate community engagement that supports authentic partnerships. The review locates the concept of corporate community engagement within levels of participation. Firstly the domain of the corporate community engagement is specified and validated through a two stage process informed by key informants located in mining communities. The study uses a Meta ethnography methodology to address the study questions. Through-out the methodological steps followed, an attempt was made to ensure that existing knowledge was incorporated as well as practical realities of corporate community engagement within the extractive industries.
\end{abstract}

Index Terms-Corporate, community, engagement.

\section{INTRODUCTION}

The extractive industries present particular challenges for both fragile states and developing nations. The exploitation of non-renewable natural resources, including oil, gas, minerals and timber has often been cited as a key factor in triggering, escalating or sustaining violent conflicts around the globe. The recent wildcat strikes in the platinum and gold industries in South Africa present the world with another example of violent conflict between the extractive industries local communities. The price paid by societies threatened by, undergoing or emerging from natural resource related violence is evident in the lives lost or touched by conflict.

Literature search for construct validation on corporate

Manuscript received April 19, 2013; revised June 19, 2013.

Pumela Msweli and Tawaziwa Wu are with the Faculty of Management and L Tawaziwa Wushe is with University of South Africa (UNISA), Midrand, and Johannesburg, South Africa aw at the University of Limpopo in South Africa (e-mail: tawaziwa@countrycool.co.zw)

Wedzerai C Mandudzo is with Social Science Community Development student at the University of Pretoria, South Africa. community engagement seeks to show the extent to which what is supposed to be measured is being actually measured in literature. It is related to the theoretical ideas behind the traits under consideration, i.e. corporate community engagement and levels of participation [1]. The review seeks to operationalize the concept of corporate community engagement by measuring several levels of participation that supposedly reflect the underlying psychological concept as captured in literature. This study is an attempt to assess how well corporate community engagement is influenced and dependent on level of participation of community members in extraction of minerals from their communities by mining industries. In lay terms, construct validity answers the question: "Are we actually measuring what we think we are measuring?" [1].

\section{RESEARCH PROBLEM}

Accrued literature shows that community social consciousness has been awakened as a result of the conflicts between corporations and local communities. Reference [2] argues that where communities are poorly engaged or excluded from the extractive dialogue within their communities, they are likely to oppose the development. Reference [3] observed that most conflict erupt because communities view their land as non-saleable and collectively held and therefore attach importance to meaningful participation in decision making processes that affect their resources. As observed by scholars such as [2] and [3], failure to engage communities may build up tensions as the corporates and communities compete for scarce resources. The study therefore seeks to analyze the relationship between engagement and levels of participation.

The competition for scarce resources is not the only source of conflict between extractive industries and local communities. With the environmental industries being accorded top priority by governments all over the world, environmental degradation is not taken lightly by local communities and civil society. In the extractive industries, [3] points out that the extractive industries tend to ignite social conflict because they make deeper environmental footprint than other industrial activities. For instance oil and gas extraction can result in leakages, spills and flaring of excess gas while building access roads can lead to deforestation. An example can be drawn from the civil war that broke out in Bougainville in Papua New Guinea. The war broke out in Bougainville due to severe environmental impacts that were as a result of copper extraction. These environmental concerns were not addressed the conflict intensified and 
connected with the independence movement in the island. Such a move resulted in the closure of the mine as infrastructure was destroyed and leaving more than fifteen thousand (15 000) people dead [4].

The conflicts captured above illustrate that the current models that corporates use for engaging communities have not worked. Possibly, the models have not worked because they are not grounded in a shared understanding of what constitutes meaningful corporate engagement within local communities. Intrinsically, the study seeks to understand the captured perceptions of local communities in literature with respect to how corporates should engage local communities. The challenge of assessing effective community engagement emanates from a range of geographical and political or institutional situations therefore this study will derive experiences and practice from diverse positions and come to a conclusion. As noted by [5] in most areas studies are being conducted at an increasing rate making it difficult for scholars to stay informed of research in all but narrowest areas of specialization. The argument is that: majority of social science areas are in less need of further research than they are in need of organization of existing research.

The study is organized around three research questions germane to corporate community engagement. The first question is: What are the factors that trigger conflict between corporates and local communities? The second question is: How do local communities define meaningful corporate engagement with local communities? The third question is shaped by evidence in literature that supports the notion that community engagement is a process of inclusive participation that supports mutual respect of values and actions for authentic partnership of people in the same geographic proximity [6]. The question is: using the levels of participation how can the awaked social energies in communities be harnessed to develop a shared value system that supports authentic partnerships.

\section{Research Methodology}

In providing taxonomy of literature reviews, [7] identified the goals of meta-ethnography to be one of the dimensions on which reviews differ. Reference [5] asserts that the aim of Meta ethnography is to synthesize qualitative studies whilst preserving their uniqueness. Reference [6], [7] and [8]'s Seven steps of Meta ethnography were followed. The steps are getting started, deciding what is relevant to the initial interest, reading the studies, determining how the studies are related, translating the studies into one another, synthesising translations, expressing the synthesis. The scope of the synthesis was a crucial question, and one that was side-stepped by the decision to provide a worked example in this exploratory study. Reference [6] made it clear that the scope of Meta ethnography often is more restricted than that of many narrative reviews, due to the wish to avoid making gross generalisations across disparate studies. This stage required that the relationships between the concepts arising from the different papers were considered but focus was kept on community engagement. Different papers were analysed for common and recurring concepts however, the main article that probed discussion is The Big Idea. Synthesis of translations was done; this stage of the synthesis could not be reduced to a set of mechanistic tasks. Through reading of the concepts and interpretations as postulated by [8] it was possible to establish the relationships between these various studies on community engagement. It became clear that the studies were not refutations of one another even when a particular concept was not identified in a particular paper. This paper is an attempt to express the synthesis on studies done across the world on corporate community engagement. The potential audiences for this kind of synthesis include practitioners in the mining industries, policy-makers and qualitative researchers. Practitioners may be more interested in theoretical and practical implications of levels of community participation on corporate community engagement; researchers may be more interested in the details of the methodology and the questions it raises for future research. A demonstration on the use of, Meta ethnography, synthesis of the results of qualitative research was done. Building on the explanations and interpretations of the constituent studies on community engagement, interpretations were developed, which at the same time consistent with the original results as asserted by [7]. It is these interpretations that justify the claim that Meta ethnography achieves more than a traditional literature review, in relation to a more focused question. They represent a conceptual development that constitutes a fresh contribution to the Corporate Community Engagement literature in search for construct validation.

\section{Corporate Community Engagement (CCE)}

There is evidence in literature that there has been international encouragement of community participation in decision making over local developments, [9] and [10]). Understandance of firms' interface with communities has become a familiar strategic concern for both firms and non-profit organizations [11]. Studies shows that existing political and economic structures are neither flexible nor supportive of greater, substantive, democracy of engagement between political and bureaucratic authorities and neighbourhood communities that are necessary in order to enhance the power of community members, [11],[12], and [13]). Corporate community engagement in extraction of minerals has always been viewed as an uneasy marriage between local communities and extraction companies, [14]. Thus, the intention in this review is to look across the corporate community engagement literature so as to discern common patterns of perception that might provide insight into the underlying drivers and payoffs of the relationship between level of participation and corporate community engagement.

Corporate community engagement is catching up among businesses operating in developing countries under the wave of corporate social responsibility (CSR). An observation from literature is that significantly, corporate community engagement discourse the world over is shifting from 'involvement' to 'investment', the latter advancing the business case, [15], [16]. This shifting paradigm depicts a calculative approach to community engagement by mining industries based on costs and benefits, revealing reciprocal 
yet unequal corporate-community relationships. This approach when implemented in already disadvantaged communities raises fears of exploitation rather than community empowerment. This review critiques the predominant approaches applied in community engagement like corporate social responsibility, stakeholder involvement and community based natural resources management and their implications towards poverty reduction and sustainable community development efforts in developing countries

At the most basic level, firms may engage by providing information, employee volunteer time or philanthropic donations [6] [10]). Within this transactional strategy, firms communicate with communities on a transactional basis. Providing information can reduce the transaction cost of, for example, a planning approval process, or help to gain access to critical resources. Although these communication strategies may sometimes be indirect, as through a trade association public information program, communication within this mode is essentially one-way, [6], [10] Altria's corporate toolkit provides a range of tactics included within this transactional approach ranging from pushing communications through education to lobbying.

The community engagement literature identifies the donation of company financial resources (philanthropy), time (employee volunteering) and skills (training of community members) as further forms of transactional engagement. Transactional engagement is based on 'giving back' through community investment and information. Indeed one of the significant differences between the public policy focused and the strategy-focused knowledge sources is the latter's inclusion of non-informational forms of society transactions. While public participation literature focuses on information transmission and sharing, the strategy literature expands this to address the transmission and sharing of money, time and skills. These forms of engagement are based on occasional interaction with a large number of partners.

Most communication and learning is a one way transfer from the firm, and the firm retains overall control of the engagement process. Benefits from the engagement can accrue to both firms and communities, but these benefits are separately accrued by both parties. In contrast, transformational engagement is the most proactive corporate engagement strategy. Literature has it that this form of engagement is characterized by joint learning and sense making [13], [11]), the joint management of projects with communities [17], [18] and community leadership in decision-making. Transformational engagement is distinctive because; organizations may achieve outcomes that were unattainable without the engagement of the community and the community takes a supported leadership role in framing problems and managing solutions. Thus, control over the engagement process is shared, and both process learning and benefits jointly emerge to both parties through the engagement process.

Transformational engagement moves beyond symbolic engagement activities and relies on authentic dialogue and critical reflectivity, [19]. Transformational engagement requires the competency to engage participants through listening and understanding, the creation of a shared organizational language so that engagement makes sense to members of the organization, and a strong connection with moving beyond talk into action [20]. Frequent interaction with a small number of partners leads to the development of trust based on personal relationships and mutual understanding.

Community needs and resources are fully integrated with the firm's decision-making processes. An example of transformational engagement is Shell's 'strategic institutional relationship' with Living Earth, an environmental education and community development NGO. The two parties had formally been in partnership for 16 years, before deliberately reframing their relationship so as to allow more transformational outcomes. Shell recognized that this involved shifting their people's thinking and culture 'from viewing an organization in a traditional contractual arrangement, to formulating an equal and enduring partnership' (www. shell.com). As Roger Hammond, Living Earth Foundation's development director put it, 'with Shell we are working with a company that is willing to share risks and work with us to build solutions in real-life situations. We are not dealing with public relation (PR) platitudes but are engaged in work that neither entity could achieve on its own. This is what we call a partnership'.

The intermediate, transitional engagement strategy is characterized by two-way communication, consultation and collaboration. This strategy is 'transitional' in the sense that firms move beyond the one-way communication of transactional approaches to engage in dialogue with communities, but do not yet reach the shared sense making and problem framing of transformational approaches. Similarly resources within transitional partnerships are seen as more than one-off transactional donations as they are shared within the collaboration, but control of the resources in these interactions remains with the firm rather than being fully shared with the community.

However, some forms of collaboration and partnership are intended to be transformational, but end up being transitional in their implementation. Indeed, distinguishing between transformational and merely symbolic or transitional forms of engagement is a significant research challenge as researchers get beneath the surface of community partnerships to identify the extent to which authentic learning, leadership and empowerment have occurred within the process [20], [21].

Our analysis suggests that at least three criteria might be used in distinguishing transitional from transformational engagement. First, transformational engagement is only realistic with very few partners due to the intense organisational effort required by both parties. Engaging with many community partners may indicate that the process is more transitional than transformational. Second, the nature of trust differs between transitional and transformational approaches. Trust in transformational engagement is based on affect and personal relationships, whereas trust in transitional engagement is cognitive and evolves based on repeated interactions between the parties. Thus, trust in transitional engagement is more fragile as either party may be managing interactions based on a tit for- tat or similar strategy, Third, transformational engagement has the possibility of not only symmetrical, independent benefits to 
firms and communities from engagement, but also of conjoined benefits accruing to both parties. This key difference between transitional and transformational approaches will be discussed further below.

The most studied form of engagement is transactional, followed by transitional and then transformational engagement. Despite the potential for learning and community participation and empowerment inherent in the most proactive forms of engagement, most of the sources address one-way communication (26 sources), and two-way dialogue and consultation. Distinguishing between 'collaboration and partnership' and truly transformational engagement was often difficult, reflecting the challenge of recognizing deep as opposed to superficial or symbolic firm strategies [12]).

NOTE: Not all sources could be identified as addressing single engagement behaviours. Some were allocated to more than one category. Others explicitly addressed a range of engagement behaviours as outlined in the community engagement continuum. The realisation is that relatively low number of studies on transformational engagement was due to academic knowledge lagging practitioner experience over time. Conventional wisdom suggests that community engagement is evolving from managing responses to particular issues, to co-creating solutions to social challenges We expected that the knowledge on transformational engagement had a later start than the earlier interest in transactional and transitional approaches, and that the lower count of transformational sources merely reflected this late start.

This may reflect a shift in the academic literature over time as conceptual calls-to-arms on engaging community in corporate decisions have gradually been surpassed by empirical studies focusing on the easiest forms of engagement to identify in practice and to measure, [17]). The availability of data might be the easiest explanation of the counterintuitive shift of knowledge generation efforts from transformational towards transactional engagement over time. As noted above, many of the latest empirical papers are large scale surveys of the most easily quantifiable forms of community engagement (philanthropy, employee volunteering and training provision). Thus, this distribution of sources over time does not necessarily mean that interest in transformational approaches is waning, merely that it is more difficult to access, interpret and publish transformational engagement studies. The shared identity of community actors [18], resources available to the community [19] the structure of community groups [21] and the nature of the social issue being addressed [17] also impact the nature and success of community engagement strategy.

The organizational context is itself located within the institutional environment, and may be framed by previous interactions with community [3]. Community engagement strategies are intended to fit with a firm's strategic position [22], and be consonant with an organization's identity [13]. More strategic approaches emphasize fit with a firm's resources [23] [24] capabilities [25] organizational structure [26]. Other typical organizational characteristics addressed within the community engagement literature, and often included as control variables, include organizational performance, age and size [20], [21]

\section{A. Participation by Communities in Development Projects}

Internationally, resources for development services are shrinking. Population pressures, changing priorities, economic competition, and demands for greater effectiveness are all affecting the course of social welfare [27]. Five aspects of participation which relates to the stance an organization promoting participation may take:

- Information - merely telling people what is planned

- Consultation - offering some options, listening to feedback, but not allowing new ideas

- Deciding together - encouraging additional options and ideas, and providing opportunities for joint decision making

- Acting together - not only do different interests decide together on what is best, they form a partnership to carry it out

- Supporting independent community interests - local groups or organisations are offered funds, advice or other support to develop their own agendas within guidelines.

The community development approach emphasizes selfhelp, the democratic process, and local leadership in community revitalization [28]). Most community development work involves the participation of the communities or beneficiaries involved [29]. Thus, community participation is an important component of community development and reflects a grassroots or bottomup approach to problem solving. In social work, community participation refers to "the active voluntary engagement of individuals and groups to change problematic conditions and to influence policies and programs that affect the quality of their lives or the lives of others" [29] Effective community participation has the potential to facilitate social and personal empowerment, economic development, and socio-political transformation [18]. However, there are obstacles like the power of central bureaucracies, the lack of local skills and organizational experience, social divisions, and the impact of national and transnational structures [18]. There is no clearcut agreement in the literature of development projects on the nature of community participation or on a prescription to ensure it. The need for community participation in development and management is nonetheless accepted and recognized in the professional literature.

\section{B. Effects of Participation on the Relationship between Industries and Communities}

Oil, gas and mining development have historically led to loss of lands, livelihoods and community cohesion for indigenous and local communities living close to the industrial activity, [30] They have been side-lining the communities from which they operate. Such an act resulted in conflicts between the corporation and the affected community, [2], [9], [27], [31] argues that where communities and stakeholders are poorly engaged or 
excluded from the extractive dialogue which affects their communities they are likely to oppose the development. The communities should be involved in the extraction dialogue from the planning stage because the scarce resources in question are viewed as Community shared resource. Ref [2] observed that most conflict erupt because communities view their 'land as non-saleable and collectively held' hence the need for inclusion in the dialogue process so that reasonable value could be attached to their 'Community shared value or resource'. Failure to take this into consideration may build up tensions as the projects and the community compete for scarce resources, [2], [9], [27], [31]. Ref [27], notes that literature about large-scale mining and development is often dominated by debates about economic, political, legislative and market structures. This realisation justifies the study on the relationship between ownership structure, board structure and corporate community engagement in the extractive industry.

In response to widespread and increasing criticism, the mining industry has started to pay serious attention to its environmental and social impacts, [9]. This has recently manifested itself in the formulation of corporate social responsibility (CSR). However, due to the fact that it's a reactionary measure by the extractive industries there is less investment and commitment on participation of community members. Historically, the mining industry has taken a 'devil may care' attitude to the impacts of its operations operating in areas without social legitimacy, causing major devastation, and then leaving when an area has been exhausted of all economically valuable resources, [2], [9], [27], [31].

Unfortunately as evidenced from literature, incidences of conflict and corporate malpractice in the mining industry cannot be consigned to history. Recent and on-going corporate-community conflicts severely test the reputations of large companies. In as much as complex relationships between mining companies and local communities is nothing new, the way that companies are now approaching these conflicts brings a different angle to the story. Literature demonstrate some of the complex social and environmental situations mining companies may face in their operations, and how difficult successful conflict resolution can be in reality to achieve if participation wasn't instilled in the initial stages of the mining operations.

\section{CONCLUSION}

From literature analysis an observation made is that two approaches are particularly useful when searching for construct validation for corporate community engagement and both requires engagement of stakeholders. In one, the emphasis is on the importance of level of participation; in the other, it is on the continuum of engagement. The first approach, participatory evaluation, actively engages the community in all stages of the evaluation process. The second approach, empowerment evaluation, helps to equip program personnel with the necessary skills to conduct their own evaluation and ensure that the program runs effectively. This section describes the purposes and characteristics of the two approaches.

\section{REFERENCES}

[1] A. Cichocki and R. Unbehaven, Neural Networks for Optimization and Signal Processing, 1st ed. Chichester, U.K.: Wiley, 1993, ch. 2, pp. 45-47.

[2] D. Pennington, Essential Personality, 2003, Arnold.

[3] S. C. W. Grzybowski, J. Bates, B. Calam, J. Alfred, R. E. Martin, and R. Andrew, "A physician peer support group," Family Medicine, vol. 35, pp. 195-201, 2003.

[4] M. Salim, "Public participation and community involvement in environmental and social impact assessment in developing countries," The International Journal of Environmental, Cultural, Economic \& Social Sustainability, vol. 2 pp. 89-97, 2006.

[5] P. A. Laplante, "Real-Time Imaging," Potentials, pp. 8-10, 2004.

[6] M. Borenstein, L. V. Hedges, J. P. T. Higgins, and H. R. Rothstein, Introduction to Meta-Analysis, John Wiley \& Sons, Ltd., 2009.

[7] G. Noblit and R. Hare, Meta-ethnography: Synthesizing qualitative studies, Newbury Park, CA: Sage, 2003.

[8] H. Cooper, Synthesizing Research: A Guide for Literature Reviews, 3rd edn, Sage Publications, Thousand Oaks, CA, 1998.

[9] K. isenhardt, "Building Theories from Case Study Research," Academy of Management Review, vol. 14, no. 4, pp. 532-550, 1990.

[10] R. H. Jenkins, Globalization, Corporate Social Responsibility and poverty International Affairs, vol. 81, pp. 525-540.

[11] R. Goodman, After the Planners, Penguin, Harmndsworth, 1972.

[12] A. D. Crane, J. Matten, and J. Moon, "Stakeholders as citizens? rethinking rights, participation, and democracy," Journal of Business Ethics, vol. 53, no. 1-2, pp. 107-122, 2004.

[13] F. Bowen, "Environmental visibility: A trigger for organizational response?" Business Strategy and the Environment, vol. 9, no. 2, pp. 92-107, 2000.

[14] Y. Fukukawa, C. Nakashima, S. Tsuboi, R. Kozakai, W. Doyo, N. Niino, F. Ando, and H. Shimokata, "Age differences in the effect of physical activity on depressive symptoms," Psychology and Aging, vol. 19, no. 2, pp. 346-351, 2004.

[15] Global Witness, All the President's Men, London, 2002.

[16] S. A. Waddock and M. E. Boyle, "The dynamics of change in corporate community relations," California Management Review, vol. 37, no. 4, pp. 125-140, 1995

[17] S. Rochlin and C. Christoffer, "Making the Business Case: Determining the Value of Corporate Community Involvement," Boston: The Center for Corporate, Citizenship at Boston College, 2000.

[18] D. P. McCaffrey, S. R. Faermen, and D. W. Hart, "The appeal and difficulties of participative systems," Organization Science, vol. 6, no. 6, pp. 603-627, 1995.

[19] C. M. Fiol and E. J. O' Connor, "Beating them or joining them: yur radiology group's path to the future," University of Colorado at Denver, Denver, Colorado, USA, 2002.

[20] K. Williams and J. Durrance, "Social Networks and Social Capital: Rethinking Theory in Community Informatics," The Journal of Community Informatics, North America, 2003.

[21] C. Shropshire, A. J. Hillman, and A. A. Cannella, "Organizational predictors of women on corporate boards," Academy of Management Journal, vol. 50, pp. 941-952, 2007.

[22] R. Abzug and N. J. Webb, "Relationships between non-profit and for-profit organizations: a stakeholder perspective," Non-profit and Voluntary Sector Quarterly, vol. 28, no. 4, pp. 416-431, 1999.

[23] S. Knox and C. Gruar, "The Application of Stakeholder Theory to Relationship Marketing Strategy Development in a Non-Profit Organization," Journal of Business Ethics, vol. 75, no. 2, pp. 115-135, 2007.

[24] A. K. Buchhiltz, A. C. Amason, and M. A. Rutherford, "Beyond resources the mediating effect of top management discretion and values on corporate philanthropy," University of Georgia, 1999.

[25] M. Kaufman and H. D. Alfonso, "Community Power and Grassroots Democracy. The transformation of social life," Zed Books, London, 1997.

[26] E. M. J. Schouten and J. Remm, "Making sense ofcorporate social responsibility in international business: experiences from shell," Business Ethics: A European Review, vol. 15, no. 4, pp. 365-379. 
[27] S. Brammer and A. Millington, "Firm size, organizational visibility and corporate philanthropy: an empirical analysis," Business Ethics: A European Review, vol. 15, no. 1, pp. 6-18, 2006.

[28] D. Kemp, "Mining, water and human rights: making the connection," Journal of Cleaner Production, 2009.

[29] T. J. Johnson, "Professions and power," Macmillan, London, 1972.

[30] D. N. Gamble and M. O. Weil, "Citizen participation," in Encyclopedia of social work, R. L. Edwards, Washington, DC: National Association of Social Workers/NASW Press, $19^{\text {th }}$ ed, vol. 1, pp. 483-494, 1995.

[31] W. Wilson and E. Swidersk, Extractive Industries and Indigenous Peoples in Russia, 2009.

[32] J. Muthuri, "Corporate citizenship and sustainable community development: fostering multi-sector collaboration in Magadi Division in Kenya," Journal of Corporate Citizenship, vol. 28, pp. 73-84, 2007.

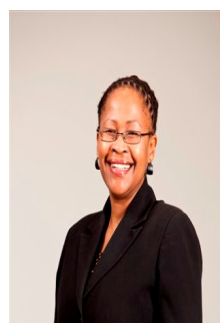

Pumela Msweli is Executive Dean of the Faculty of Management and Law at the University of Limpopo in South Africa. Her PhD is from University of Exeter (UK). She has taught at University of Witwatersrand, University of KwaZulu-Natal and University of South Africa. An accomplished researcher, professor Msweli has written extensively and has published her work in local and international journals. Her current research interest is in economic transformation and development finance.

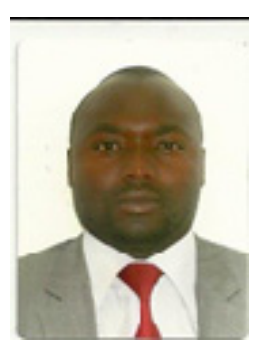

Tawaziwa Wushe is with University of South Africa (UNISA), Midrand, Johannesburg, South Africa; Executive Masters in Business Administration (EMBA) with Eastern and Southern Africa Management Institute (ESAMI), Arusha, Tanzania 2008; Bsc Honours in Economics (University of Zimbabwe), Harare, Zimbabwe 2004. $\mathrm{He}$ is an Executive Chairman of Country Cool P/L, Board member of Marange Resources $\mathrm{P} / \mathrm{L}$, and has over 8 years in project management and leadership. strategic management. His interests are in corporate governance and

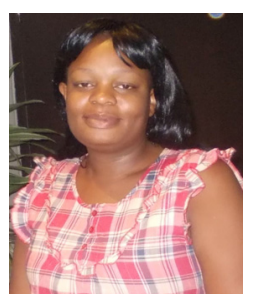

Wedzerai C Mandudzo holds a Bachelor of Arts Geography degree (Masvingo State University, Zimbabwe, 2006) and Honours degree in community development community development (University of Pretoria, South Africa, 2011). She is Zimbabwean studying Master of Social Science Community Development student at the University Of Pretoria, South Africa. Her current research interests are (1) Development and transformation of nations especially sub-Saharan Africa; (2) Theories and strategies of community development; (3) redevelopment of marginal low-income neighborhoods. Wedzerai $\mathrm{C}$ Mandudzo is an independent consultant and trainer of sustainable rural livelihoods and development projects. 